\title{
backstory
}

\section{Arcs to ashes}

\section{Susanne Straub and colleagues examined teaspoons of 42-million-year-old volcanic ash to elucidate the impact of plate tectonics on arc magmatism.}

\section{What was the objective of the work?}

Volcanic arcs - chains of volcanic islands or mountains - form in subduction zones, where one lithospheric plate is dragged beneath another. This complex environment is reflected in the chemistry of the arc magmas, which contain components from the subducting plate and the upper plate. Our main aim was to determine whether the composition of arc magmas, erupted from the Izu-Bonin arc in the northwest Pacific Ocean, has been recording the composition of a plate that has been subducting for the past 42 million years.

\section{Why did you choose this particular location for the fieldwork?}

In order to study arc evolution over such a long period of time, we needed a coherent, time-precise and highly resolved rock record. The Izu-Bonin arc in the northwest Pacific Ocean is one of the few volcanic arcs for which a 42 -million-year record is available.

What sorts of samples were you after? We wanted a temporally accurate record of volcanic activity and magmatic composition. Explosively erupting volcanic arcs produce large amounts of volcanic ash; wind carries this ash into nearby oceanic basins, where it accumulates. In 1989, a deep-sea drilling expedition onboard JOIDES Resolution recovered sediment cores - containing these ash beds - from the sea floor. We used the ashes to trace the chemistry of Izu-Bonin arc magmas back in time.

\section{Did you encounter any difficulties?}

After separation and cleaning, the usable ash particles occupied less than the tip of a teaspoon. Thus, we needed to apply and

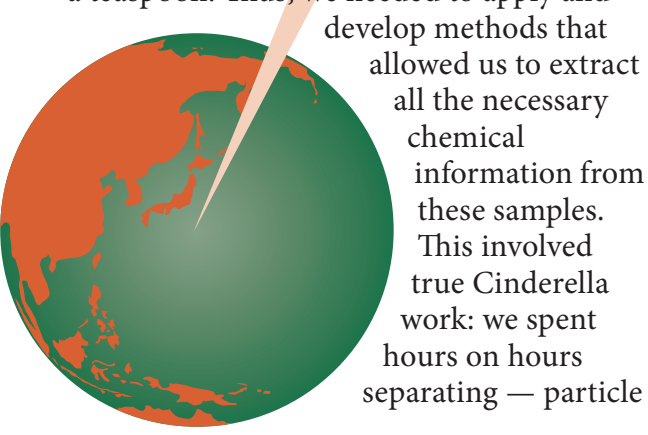

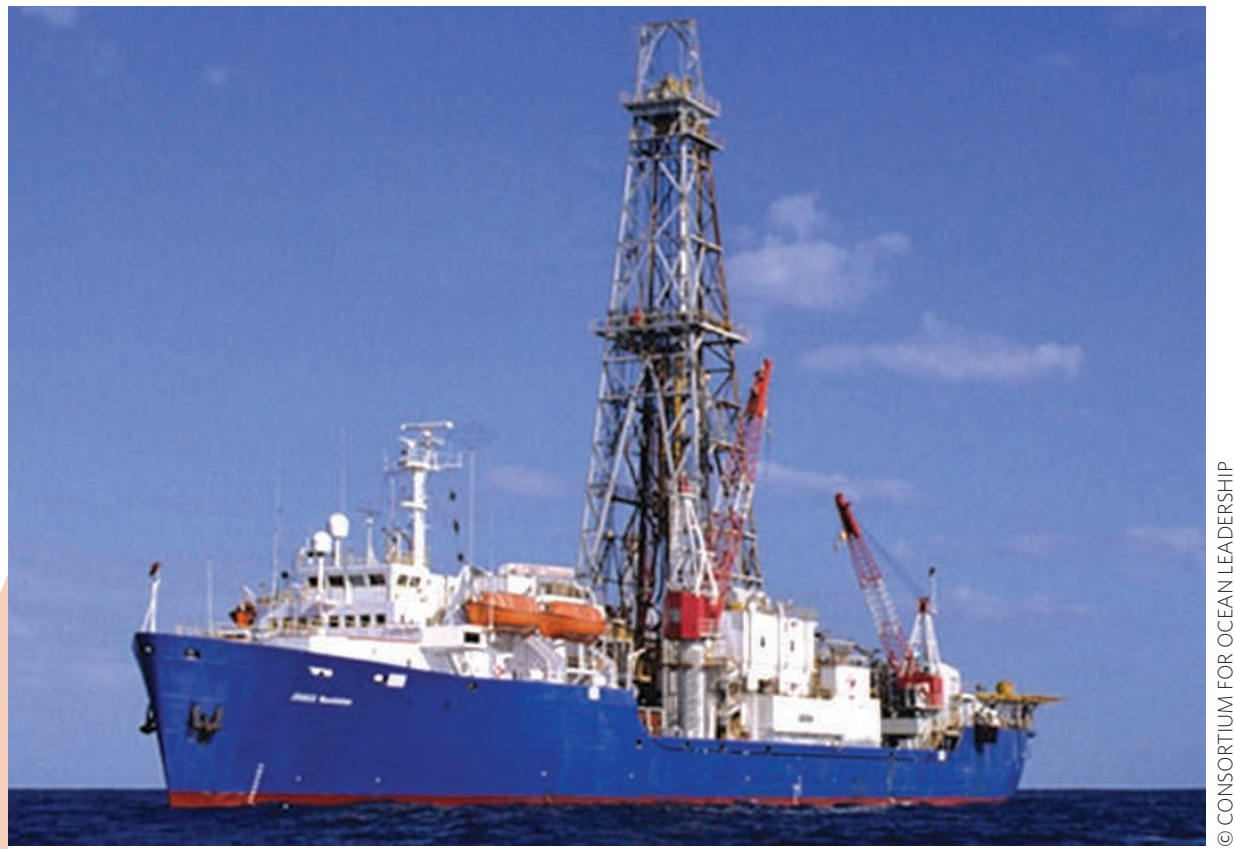

JOIDES Resolution: the drilling vessel used to obtain sediment cores from the sea floor in the northwest Pacific Ocean.

by particle - the good ash from the bad. And, more often than not, the usable material was good for only one analysis, which caused some anxiety to the analyst.

\section{What was the highlight of the project?}

Cherished highlights include those rare times when we got to go out to sea, and saw, from the rolling ship, a perfectly shaped volcanic cone breaching the incredible blue of the tropical ocean. Scientifically, the highlight of our study came when, after many years, we began to realize that Izu-Bonin arc magma did indeed contain information about changes in plate tectonics during the Cenozoic era (which stretches back 66.5 millions years).

\section{Any low points?}

Piecing together more than 40 million years of arc history turned out to be a long-term enterprise that consumed more than one research grant. Sampling of the ash beds started in 1992. To complete the study, we had to repeatedly apply for research grants; continuation of the project was by no means guaranteed.

\section{Did the trip give you any ideas for future research projects?}

It feels like we have barely begun. We worked on the evolution of one oceanic arc, out of the two dozen or so major volcanic arcs that exist around the globe. We already know that each volcanic arc has its own history, and its own way of responding to regional tectonic and environmental change. The greatest challenge lies in determining the environmental impact of greenhouse gases (for example, carbon dioxide) and aerosols that are emitted by volcanic arcs into the Earth's atmosphere. Did arc volcanism contribute to climate change in the geological past?

This is the Backstory to the work by Susanne Straub and colleagues, published on page 286 of this issue. 